\title{
Teachers' Performance Motivation System in Thai Primary Schools
}

\author{
Sarojn Pasathang ${ }^{1}$, Kowat Tesaputa ${ }^{1} \&$ Pattananusron Sataphonwong ${ }^{1}$ \\ ${ }^{1}$ Faculty of Education Mahasarakham University, Thailand \\ Correspondence: Sarojn Pasathang, Muang Mahasarakham District, Mahasarakham Province, 44150, Thailand. \\ Tel: 66-086-0630-4901. E-mail: sarojn.pasathang@gmail.com
}

Received: November 17, 2015 Accepted: February 9, 2016 Online Published: June 28, 2016

doi:10.5539/ies.v9n7p119

URL: http://dx.doi.org/10.5539/ies.v9n7p119

\begin{abstract}
This research aims to 1) study the present conditions and desirable condition of the motivation systems as well as how to find methods for motivating the performance of teachers in primary schools, 2) develop a motivation system for the performance of teachers in primary schools, 3) study the effects of using the motivation system for compliance with work of the teachers in primary schools by using research and development process. The research was consisted of three phases: Phase 1 the study of current conditions and desirable conditions of motivation system and methods for motivating the performance of teachers in the schools under the Office of Basic Education. Questionnaires were used to collect data from the sample which was consisted of 1,016 school administrators and teachers. Phase 2 development of motivation system for the performance of teachers in primary schools. The system was later validated by nine experts. Phase 3 results of the study on motivation system after implementation in a primary school. Data was collected from eight school administrators and teachers. Instruments in collecting data were: 1) questionnaire, 2) semi-structured interviews,3) evaluate form of operational level, 4) evaluation form of satisfaction. Statistical used in data analysis were percentage and standard deviation.

The results showed that: 1) the current conditions of the motivation system for the performance of teachers by the input factor was at a moderate level, by the process factor was at a high level, and by the output factor was at a moderate level. As the desirable conditions, all three factors were at the highest level. 2) The motivation system for the performance of teachers in primary schools that the researchers have developed consists of six sub-systems, including: work-based motivation, award-based motivation, good communication, creating organizational relationship, environment in the workplace, workplace fairness. The input factors included: administrators, teachers, materials, and technology. Output included work performance standard and personal performance standard. 3) Results after the implementation of the system revealed that the teachers were motivated to perform at a high level and their preference for a motivation system was also at a high level.
\end{abstract}

Keywords: motivation system, teachers' performance, Thailand's primary schools

\section{Introduction}

\subsection{Introduction to the Problems}

Teachers in Thailand are facing various kinds of professional problem. According to the research report by the Secretariat of Education (2008; 2010a; 2010b) on the issues of teachers career from 2008-2010, it found that the teachers were inefficient in teaching, teachers had truancy problems, teachers lacked of motivation to work, teachers lacked competence in teaching field, teachers had to change jobs frequently. Parts of that result were because teachers had no aptitude for teaching in some subjects and had too many extra missions. Some teachers lacked commitment to their own development. Many teachers upheld the traditional work. They even lacked of professional morale; some teachers refused to have behavior modification. Teachers made professional merits by the encroachment of learners' hours. Teachers could not attend to teach for the full session as normal hour. Personal attitudes were also affected. Teachers were in debts to the cooperative credit union and external financial institutes. Some teachers did not believe in career and made transitions to another career. Many teachers need extra time to work to earn extra money. Teachers had no pride in the occupation which chose to join the early retire projects. The workload was also another reason. Teachers had too many special tasks to perform and teach too many lessons. Teachers did not have time to work and help students individually. Teachers teaching activities did not meet the needs of most learners. They tended to buy ready-made lesson plans. They 
hardly had motivation to teach for good results.

\subsection{Explore Importance of the Problem}

The issue of teachers on the status and quality teachers can be summarized as follows.

1) Problems with the teachers such as issues relating to the budget promotion and support, strengthening of teacher morale, facilitating of teachers, and evaluation of performance of teachers. Teachers' performance motivation was at a low level.

2) The problem with administration of teachers. The problems related to deployment of teachers, inefficiency of the management system, monitoring and evaluation, lacking of resources, lacking of motivation by administrators. Thus, the administration and management of schools should focuses on creating a way to contribute to the successful aims. It is absolutely necessary to seek cooperation and draw potentiality in teachers' expertise. Teaches should also sharing the plan by joining operations and assessment. This would allow administrators to perform effectively and efficiently. In addition, administrators must have the ability to manage school by leadership skills to be the model for the people. Motivation is the factor that encourages the performance of teachers for changes in a positive way. Satisfaction in practice from motivated teachers could help to achieve the objectives and goals of education efficiency with sustainability. It is necessary to take into account the individuality and encouragement of teachers to use their intelligence to create jobs performance. (Hannakin, 1987, p. 6, Kasemsin, 1988, p. 219; Ruthcharoen, 2010, p. 74; Ketsakorn, 2011, p. 175)

\subsection{Describe Relevant Scholarship}

Motivation is important to the performance of teachers because each teacher is different. But the main thing of motivation is to encourage teachers to work on duty. The motivated teachers tend to have a good morale and bring about the cooperation in their work. Motivation is the guideline in level of performance; teacher will have consistent performance and higher than the ones without motives. The motivated teachers tend to have peaceful mind to act further with a desire to do something good. Teachers who are motivated do their works to achieve goal with higher ambitions, commitment, and initiative. They even put efforts to improve themselves further. Administrators play a key role in the management of school to achieve more efficient and effectiveness. It requires both art and science to motivate school teachers. Administrator must oversee and promote motivation for teacher performance to encourage them in the assigned duty with the best attempts. Motivation is important to school administrators by they must find a way to create motivation for teachers. The teachers with motivation are encouraged to perform the duties in collaborative work manner for school efficiency and effectiveness. (Ryan \& Deci, 2000, p. 200; Wool-folk, 2004, p. 350; Somprasong, 1993, p. 120; Wonganutararoch, 2010, p. 111; Uppaphai, 2011, p. 104; Wongkiatkajorn, 2010, p. 36; Panpae, 2011, p. 173)

From the above, it can be seen that the current state of motivation for the performance of teachers still lack of effectiveness. It is crucial that researchers must develop the innovation in motivation system for teachers in primary schools. The developed system will make the teachers' practice to be higher level, therefore all above problem will be reduced. Administrators have to manipulate motivation approach of each teacher in specific occasion. Also they need to encourage teachers for motivation for the right performance according to the needs of teachers who are motivated. (Hopkins, 2001, p. 29; Ruthcharoen, 2010, p. 324; Wonganutararoj, 2010, p. 121; Kohtbantau, 2011, pp. 17-19; Sunhachavi, 2011, p. 78).

\section{Method}

The Objectives of the research is as follows: 1) to study the present and desirable motivation systems and methods for motivating the performance of teachers in primary schools, 2) to develop a system of motivation for the performance of teachers in the primary school, 3) to study the effects of the developed motivation system on teacher performance in the primary schools.

\subsection{Research Methodology}

This research uses the research and development process as a technique combines with the mixed methodology. It combines thinking method and methodologies, both in quantitative and qualitative research in order to answer the research question completely. Area and target group of this study include school administrators and teachers in primary schools under the Office of Basic Education for 1,016 people in total samples of the research.

There are two types of research tools: 1) development tools for the operation development, 2) data collection tools: (1) Questionnaire (2) semi-structured interviews (3) operation evaluation, and (4) a satisfaction rating test. The statistics used for data analysis were percentage, average, and standard deviation. Analysis focused on prioritize of all needs bu using the formula of Modified Priority Needs Index (PNI modified) and the t-test. 


\subsection{Research process}

Research process was divided into 3 phases.

Phase 1 study of the current conditions and desirable conditions of the motivation system and how to build it for the performance of teachers in primary schools. Details were as follows:

Step 1 study of theory, textbooks, and related research. The data were used to synthesize and design the elements of motivation system for the performance of teachers in primary schools. By creating the questionnaire, it could study the present and desirable system of motivations and ways of motivating the performance of teachers in primary schools.

Step 2 Study of current and desirable conditions of the system of motivations and ways of motivating the performance of teachers in primary schools.

1) Population and sample

1.1) The population in this study were the elementary schools under the Office of Basic Education for total number of 29,689 schools.

1.2) The samples used in the study were the elementary schools of 508 schools, selected by using the multi-stage random sampling method. (Srisa-ard, 2000:44). School administrators and teachers in each primary school were the data providers for total of 1,016 people.

2) Data collection tools

A questionnaire on the current and desired conditions of motivation and how to motivate the work of teachers in primary schools was used. It was verified for the accuracy of content and the IOC (Index of Item Objective Congruence) (Gamkhet, 2008, p. 220). The tool was later verified by five experts for its significance by using coefficient alpha by Cronbach Method (Cronbach. 1990, pp. 202-204). It found that reliability of the tool for current conditions has the confidence of 0.95 level and desirable conditions has the confidence value of 0.96 .

3) Data collection

Data collection for the study used a questionnaire along with the letter of permission from the Faculty of Education Mahasarakham University. This used to ask for rights from respondents to provide cooperation in data collection procedure. The questionnaires were delivered and returned by mail.

4) Data treatment

The qualifying questionnaires were examination for their completion in answering according to the specified criteria.

\section{5) Data Analysis}

Computer program was used in analysis of current and desirable conditions for the system of motivations in the teachers' performance in the primary schools. Statistics used to examine the mean), standard deviation, and priority needs index (PNI) (Wongwanich 2015: 279). These statistics was used to interpret the results by the standard deviation (Srisa-ard 2000: 100).

Phase 2 development of motivation system for the performance of teachers in primary schools.

Details were as follows:

Step 1 Study of the motivation system for the performance of teachers in the Best Practices Award schools by selecting two specific schools. The criteria of school selection was passing of the 2 nd round evaluation by the Office for National Education Standards and Quality Assessment at an excellence level, high student achievement level, and regional outstanding performance.

1) Information Provider

Data providers include school administrators and teachers in schools with the Best Practices Award which were: 1) Lamplaimas Pattana School, in Khok Klang Sub-district, Lamplaimas District, Buriram Province, and 2) Ban Nong Ngon Phanao Mittraphap 126, in Sawangdandin Sub-district, Sawangdandin District, Sakonnakhon Province

\section{2) Data collection tool}

A semi-structured interview that the researcher developed which covered issues in motivation elements for the performance development of teachers in the primary education schools.

3) Data collection 
The researcher collected data covered by official letter from the Faculty of Education, Mahasarakham University. Letter asked for cooperation in data collection. Researchers telephoned to make an appointment for an interview date and time.

4) Data treatment

The researchers synthesized information from interviews conclusion and content.

Step 2 Draft of motivation systems for the performance of teachers in primary schools.

Experts determined the suitability and feasibility of the motivation system for the performance of teachers in primary schools. Details of the operations in this process were as follows.

1) The data obtained from the analysis of the PNI, percent, and average in the first phase, along with the Best Practices schools into consideration to design a system of motivations for the performance of teachers in the primary education school

2) Create the draft of motivation systems for the performance of teachers in primary schools, with a manual of motivation system for the performance of teachers in primary schools. Both the draft and manual were checked by the thesis advisor for the integrity of the content.

3) The motivation system for the performance of teachers in primary schools and a manual were provided to the experts to qualify the appropriateness and feasibility.

3.1) data providers

Nine of the experts were to determine the appropriateness and feasibility of motivations system for the performance of teachers in primary schools.

\section{2) data collection tools}

It was the form on assessment on the appropriateness and feasibility of the motivations system for performance of teachers in primary schools. It was a three-level rating scale which ranged by: not appropriate, not certain, and appropriate. Also, it was the open-ended questions. Experts wrote their issues rand recommendations to improve the system of motivations to guide the practice of teachers in primary schools.

\section{3) Data Collection}

The researcher collected data personally by traveling to meet all experts to obtain their feedback.

\section{4) Data treatment}

The experts scored their evaluation according to the scoring criteria.

\section{5) Data Analysis}

A 3-level rating scale was used determine the appropriateness and feasibility of the system. The model was analyzed by using average and standard deviation (Srisa-ard, 2000, p. 100). 


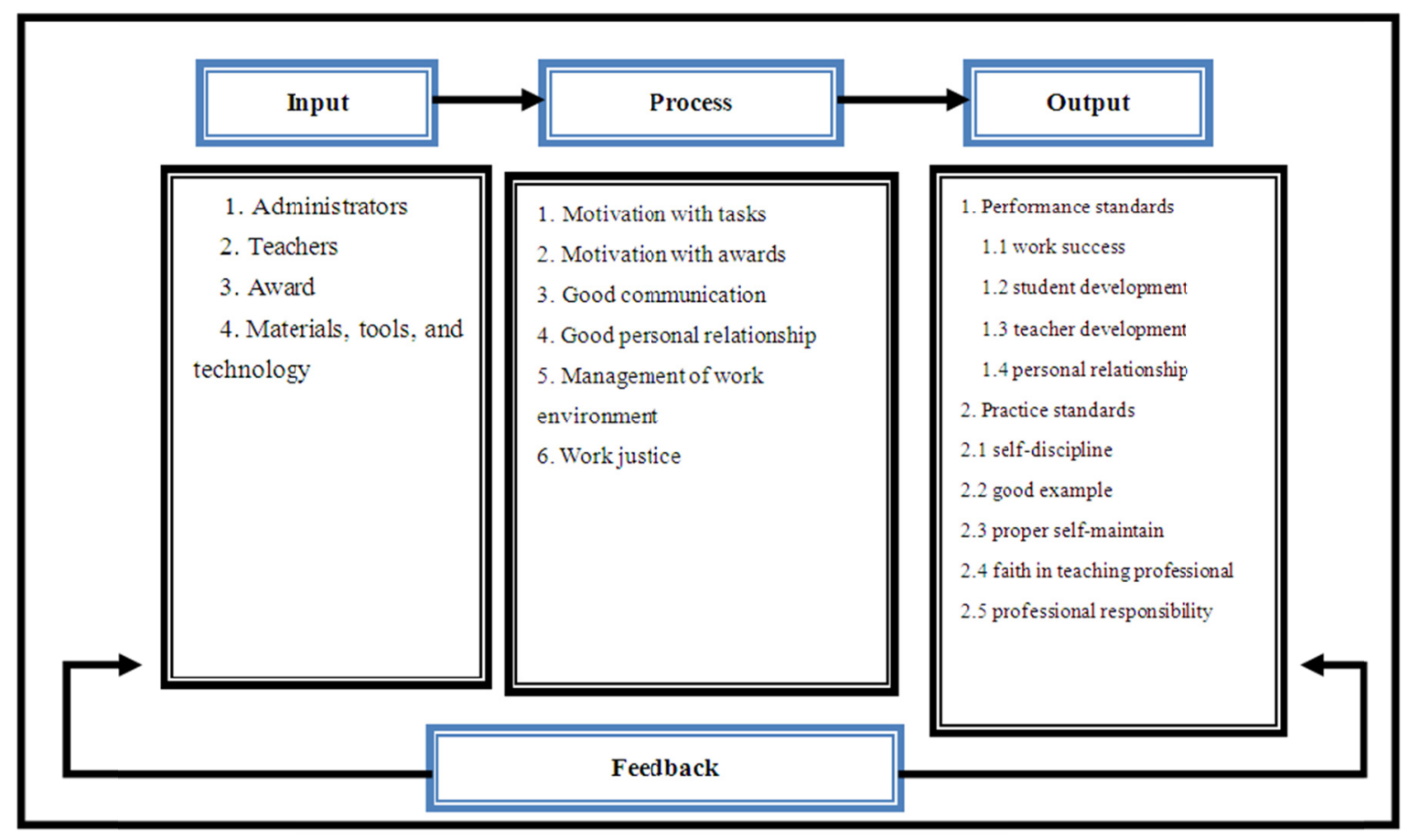

Figure 1. Motivations system for performance of teachers in primary schools

Phase 3 Study of the implementation of motivation system for the performance of teachers in primary schools.

Details as follows:

Step 1 the motivation system for the performance of teachers in primary schools was implemented to one school.

Step 2 analysis and presentation of the introducing of motivation systems for the performance of teachers in primary schools.

1) Information Provider

The data providers for the study of motivation system for the performance of teachers in primary schools were included: school administrators and teachers in primary schools under the Office of Basic Education. One school was selected by the Purposive Sampling Method. (Srisa-ard, 2000, p. 41). This data was analyzed as the qualitative case study.

2) Data collect tool

The tool used in this phase was implementation of the motivation system for performance of teachers in primary schools. The trial system was used along with it described manual.

Implementation of the system

2.1) Evaluation of performance standards and practice standards.

2.2) Assessment of the performance of as of six subsystems.

2.3) Measuring satisfaction of the motivation system for the performance of teachers in primary schools.

3) Data collection

Data collection during trial stage of the motivation system for the performance of teachers in elementary schools was conducted as follows.

3.1) Cover letter from the Faculty of Education, Mahasarakham University was requested. It asked cooperation from the schools to administer the trial of the motivation system for the performance of teachers in primary schools. Data was collected after permission granted.

3.2) Researchers conducted a training to clarify school administrators with direction of the motivation system for the performance of teachers in primary schools.

3.3) trial period was two months. Evaluation of the trial was conducted after that period. 
3.4) Monitoring and evaluation on the use of motivation systems for the performance of teachers in primary schools. The research was conducted as follows:

I) Evaluate the performance of teachers. Consider and compare the performance as before and after the introduction of motivations system. Researcher used the tool to assess teachers' performance.

II) Evaluate the performance of six subsystems from the motivation system for the performance of teachers in primary schools.

III) Assess the level of satisfaction with the performance of the teacher from the motivation system by four elements: input, process, output, and feedback. Eight school administrators and teachers were assessed.

4) Data treatment

4.1) Evaluation of the operational performance standards and the self-practice standards were evaluated by three people including: school administrators, colleagues, and teachers themselves. The assessment was based on scoring criteria.

4.2) Evaluation of the performance of teachers according to six subsystems were evaluated on the performance evaluation form by two people including: school administrators and teachers themselves. The assessment was based on scoring criteria.

4.3) Measuring satisfaction toward the motivation system for the performance of teachers in primary schools. The evaluation was based on the satisfaction form and by two people including: school administrators and teachers themselves. The assessment was based on scoring criteria.

5) Data Analysis

The statistics used in this study are as follows.

5.1) Statistical comparison of the average, using Paired $\mathrm{t}$ - test.

5.2) Basic Statistics included: average ( $\bar{x})$ and Standard Deviation (S.D.)

5.3) Five-level Rating Scale as a data analysis tool obtained from the evaluation of performance standards and practice standards of teachers by using average and standard deviation (Srisa-ard, 2000: 100).

5.4) Five-level Rating Scale as a data analysis tool obtained from the evaluation of six subsystems by using average and standard deviation (Srisa-ard, 2000: 100).

5.5) Five-level Rating Scale as a data analysis tool obtained from the evaluation of satisfaction of school administrators and teachers by using average and standard deviation (Srisa-ard, 2000: 100)

6) Tools used in the research

The research has two categories of tools:

I) Tools for data collection which were different depending on the stage of the research (1) questionnaire was used to collect data from the Phase 1 (2) semi-structured interviews was used to collect data from informants in Phase 2 (3) Evaluation level of performance and satisfaction was used to collect data from the Phase 3.

II) Tools for implementation which was the manual and system of motivations for the performance of teachers in the school. These tools were consisted of six subsystems.

\section{Results}

\subsection{Results of Motivation System for the Performance of Teachers in Primary Schools}

1) The study of current conditions and desirable conditions of the motivation system of teachers in primary schools, it found that current conditions of the system were ranked respectively: motivation by work, motivation by award, good communication, environment management, and building of good relationships. Most desirable conditions were ranked respectively: good communication, motivation by award, environment management, creating a good relationship, and motivation with work. Survey of teachers needs on motivation was ranked respectively: building a good relationship, environment management, good communication, reward assignments, and work fairness.

2) Motivation system for the performance of teachers in primary schools that the researchers had developed includes:

a) Input factors: administrators, teachers, materials, equipment, and technology.

b) Process factors: motivation by work, motivation by award, good communication, building good relationships, 
environment management, and fairness in work.

c) Output factors: 1) performance standard which is achievement of the work, commitment to student development, self-development of teachers, and interpersonal relationship. 2), performance standard in self-discipline which is being a good role model, properly maintain of teaching profession faith.

d) Feedback factors: which included: performance reports and recommendations reports, as well as develop as recommendations received.

3) Implementation of motivation system for the performance of teachers in elementary schools

a) Performance of teachers can be divided into two areas:

1) Standard levels of work performance by overall levels were at high level and also higher than the previous performance.

2) Standard levels of self-performance by overall levels were at high level and also higher than the previous performance.

b) Evaluation of the six subsystems by overall levels were at high level and also high in individual level.

c) Satisfaction level of school administrators and teachers to the motivation system, by overall levels were at high level.

\section{Discussion}

The results of the study were discussed as follows:

1) The current motivation system for the performance of teachers in primary schools was overall operated at the moderate level. Desirable conditions were at the highest level. This clearly showed teachers' ability to work. Yet they lacked of motivation to work, lacked of continuous supervision; therefore teachers should be given motivations in performing their tasks. This was consistent with Kamini (2011, p. 74) who conducted a research to study the behavior of school administrators affecting the motivation of employed teachers in municipal schools the Chon Buri province. It was found that 1) the leadership behavior of the administrators in the overall level was in a high level. When they were sorted descendingly, it found. Leadership Behaviors support participatory leadership behavior towards success. 2) motivations for teachers, municipal employees in the province of Chon Buri. Overall the level by an average of descending to such engagement. Demand success and power requirements 3) the relationship between the leadership of school administrators have a positive correlation with employee performance motivations for teachers municipality in the province of Chon Buri. This research was consistent with the Batprakhon $(2014$, p. 66), research on the relationship between the motivations in the work of the teachers of the schools under Buriram Office of Primary Education Area 3. It found that 1) the overall motivations for the performance of teachers were in high level, 2) the effectiveness of schools was overall in high level, 3) the relationship between motivations, and performance and effectiveness of teachers in schools were positively correlated.

Moreover, Klongklaew (2012, p. 188) studied on the development of strategies for motivating the performance of teachers in medium-size secondary schools in Kamphaeng Phet. The results showed that: 1) Needs for motivation in the performance of teachers in secondary schools were at high level. Considering individual factors, it was found that success in the life was the highest need. 2) Development of strategies for motivating the performance of teachers were found in six key strategies as follows: 2.1) operation of work, 2.2) responsibility of work, 2.3) respect of work, 2.4) progress of work, 2.5) physical factors, 2.6) success in life. 3. Evaluation of strategies for motivating the performance of teachers in secondary schools in Kamphaeng Phet, it found that in aspects of appropriateness, feasibility, and usefulness were in the high level in overall evaluation. More motivation study was also consistent with Tien $(2008$, p. 17) which was a research on motivation in creating academic research of professors in universities in Taiwan. It is believed that changing of the motivation system could change the behavior in the research of the professors. The study found that the incentives were the motivation to research professors. Incentives were occurred both inside and outside the organization. The most innovative research professors were the ones with $\mathrm{PhD}$ qualifications. State-university professors were likely to produce the work more than the professors in private universities. In addition, policy on faculty development was important and necessary.

2) The motivation system for the performance of teachers in primary schools that the researcher had improved, it found that the Input features were included: administrators, teachers, awards, materials, and technology. Process features were included: motivations with work, motivation with award, good communication, good relationship, environment management, and fairness in work. Productivity features include: 1. Standards of Work 
Performance. There were four sub-components: 1.1 success of work, 1.2 commitment in student development, 1.3 teacher self-development, and 1.4 interpersonal relationship. 2. Standard of Self Performance. There were five sub-elements: 2.1 self-discipline, 2.2 role model, 2.3 properly self-maintain 2.4 faiths in the teaching profession, 2.5 accountability in the teaching profession. Feedback features were included: 1. reporting and recommendations, and 2. improvement to recommendations. This result was consistent with Sonkanok (2010, p. 227) which studied on factors that affect self-motivation to develop research creation among faculty of the private universities. It found that the factors that affect the motivation to develop their creative contributions among the academic faculty of the private universities consisted of 8 elements and 64 variables. Eight of the elements were included: 1) academic atmosphere, 2) pride in work, 3) rewards and satisfaction, 4) institutional supports, 5) institutional faith, 6) role and responsibility, 7) supportive colleagues and family, 8) system of quality assurance. The development strategy for self-motivation in creation of academic work among faculty of the Payap University was involved with the following factors: 1) academic atmosphere, 2) pride in work, 3) institutional supports, 4) rewards and satisfaction, 5) institutional faith. The strategy was classified to institutional strategy, agency strategy, and personal strategy.

This research was also consistent with Kocabas (2009, p. 724) which focused on the effect of the factors that motivate the teacher performance. It found that there were 15 different factors involved as follows: 1) feeling of safety from good atmosphere in the workplace, 2) success of learners, 3) job satisfaction of teachers, 4) self-respect of their dignity or pride, 5) recognition by society and by individuals in the same circles, 6) pride in their successes, 7) good relationship between colleagues, 8) sense of self-esteem and self-respect, 9) pride in the institutions, 10) appropriate work schedule, 11) reasonable wage/salary, 12) good management of the institution, 13) fairness and standard in organizational culture, 14) supports from family and colleagues, and 15) good welfare for health, safety, retirement. In order to accomplish the goals of the institution, there were three factors as follows: 1) participation in the decision making process, 2) professional advancement, and 3) being recognized as a great model. Finally, it was also consistent with the research of Heisinger (1994, p. 291) which studied on the factors that motivate teachers want to work for their own professional development. The study found that there were five factors as follows: 1) self-driven personal development, 2) social needs factors, 3) physical factors, 4) status factors, and, 5) safety factors.

3) The implementation of motivation system for the performance of teachers in primary schools, it found teachers had improved their performance standards and self-standards. Output of the system implementation had achieved the following results: 1) performance standards which included success on the job, commitment to student development, teacher self-development, and interpersonal relationship, 2) self-performance standards were included: being a good role model, properly self-maintain, faith in teaching profession, and accountability in the teaching profession. This system was suitable for the development of motivations for the performance of teachers in primary schools. After considering implementation of system trial, such variations resulted from development of teachers could eventually benefit school.

The results were consistent with Srinil $(2009$, p. 84), which studied the developing guidelines on the practice of motivating staff in small schools. It was the case study of three primary schools; Wat Lad Rahong School, Wat Tham Mai School, and Wat Sri Pawang School. It found that the problems were related to shortage of teachers, personnel, heavy teaching loads, lacking of direct major teachers, insufficient self-development, living expenses and liability issues. Budget problems were related to: limited budget allocation, shortages of material and equipment. Academic conditions were related to: lack of academic planning and learning management, lack of resources (equipment, teaching materials, media, technology and educational innovation), and insufficient supervision for teachers on monitoring and verification. Moreover, the achievement of students is relatively low. General administrative issues were on: delay in management procedures, unready environment for teaching. A malfunctioning school building may harm to students. From such conditions, it brought the problems to teachers' morale. The guideline to construct and develop the motivation for the performance of teachers in small schools was composed of three stages: 1) planning, 2) implementation, and 3) monitoring, evaluation and reporting. From the trial of that motivations system on the schools, it showed improved results. School directors and teachers could implement accordingly to the guidelines of motivations. They all agreed that it suited the small size schools. Evaluation on the use of the guideline for creating motivation of staff in small schools, the results showed that school directors and teachers were satisfied with the motivations system of staff performance of staff in small schools.

Moreover, this was consistent with Mailard and Alkins (2004, p. 373) on study of culture change and the expansion of academic expectations which were that factors that influence academic work in small Christian colleges and universities. The Institute will focus primarily on teaching. Motivating teachers to attend academic 
activities is the mission of the management culture of private higher education institutions in which less than 5000 students. They had different characteristics from larger state universities. Most professor of Christian university tends to have more workload, serving various committees, advising the students, participation in the community activities. Although there were some professors who achieved their academic mission, the study found that the important motivation to the professor was the internal motivation. Nevertheless, role of the executive was necessary to support academic work of professors. Research on motivation revealed associated factors. From Myers (1993, p. 54) who studied the satisfaction factors in working in adult education and higher education workers to know the key elements associated with the satisfaction. It found that the library director had less satisfaction in the work than standard. In comparison between female and male director, most female director had more satisfaction in the workplace than male colleagues. Elements that had satisfied the most were: various opportunities to work with, continual work, ability on opportunity management. The least satisfaction factors in working condition were: operational policy, career opportunities, and respect recognition. For the relationship satisfaction factors were associated with: current position, ages of colleagues, budgets, and salary. They were positively correlated with satisfaction in their work, while the numbers of years in the working were contrary related to satisfaction.

\section{Suggestion}

Research of motivation systems for the performance of teachers in primary schools found that overall level were in high level. Suggestions for bringing research to implement were as follows:

1) The implementation of motivation system to use for the performance of teachers in primary schools.

1.1) The researchers determined how to conduct research as a motivation system for the performance of teachers in primary schools. This was a research and development approach. Motivation is necessary to perform the job of a teacher to reflect the changes resulting from the implementation of the system in school. They should take into account the context of each schools in the implementing the system. Because the operation of the system is a continuous cycle, it needs planning, implementing, and evaluating the consequences by the participation and cooperation of all the teachers in the schools. In addition, Green et al. assert that self-concept and self-system play important role in motivating school teachers as they are key drives for motivation mechanic (2012, p. 1111). Therefore, implementation of research and development can fix and improve the development of performance of the education system to be effective as well as to improve the achievement of students.

1.2) The results of this research was the motivation systems for the performance of teachers in elementary schools which contains elements of the system for motivation in the performance of teachers. The administrators can be used as a tool to create motivation for the performance of teachers in schools. So that schools where will be using this system are based two conditions: willingness and readiness of teachers in schools; duration to motivate the work of teachers. The appropriate duration of operational efficiency should be at least one semester, and it should be carried out continuously.

2) Research of the motivation system for the performance of teachers in primary schools had found that it could be a motivation system to practice in schools. Thus, the following suggestions were:

2.1) administrators should emphasize priority to the performance of teachers in schools by advising and mentoring on teachers periodically, in order to provide maximum efficiency in schools.

2.2) administrators should summarize the results and evaluate the performance of teachers by each sub-system to reflect the performance of teachers as a whole.

2.3) administrators should plan and perform with the compliance system process. They need to continually follow, make a brief evaluation of work regularly, and consistently acknowledge the performance.

\subsection{Suggestions for Further Research}

1) The research developed at this time was the trial stage in a research and development process. It was used to implement the motivation system of teacher in practice. Therefore, it should have conducted further research using the action research process by the experiment design in different school sizes. This should include relational system, hypothesis, design, and method as Nesselroade and Cattell (2013, p. 69) suggested.

2) There should be a long-term research, with positive reinforcement, monitoring and evaluation, and continual encouragement. Data collection on the subjects should be both quantitative and qualitative approach. Achievement of permanent behavioral changes will be sustainable development. However, as Watzke concerns, longitudinal research has complexity to the nature of teachers whom researcher aimed to investigate their motivation. Specifically, concerns-based theory is suggested to include in research (2007, p. 106). Moreover, 
Dörnyei and Ushioda's (2013, p. 5) positive cycles of high motivation is suggested to include as related factors are correlated: 'high motivation $\rightarrow$ high achievement $\rightarrow$ high motivation'.

\section{References}

Batprakhon, N. (2014). Relationship of Teachers Performance and Effectiveness in Schools under Jurisdiction of Buriram Office of Educational Service Area 3 (Master thesis, M.Ed. in Educational Administration, Graduate School of Buriram Rajabhat University).

Cronbach, L. J. (1990). Essentials of Psychological Testing (5th ed.). New York: Harper \& Row.

Dörnyei, Z., \& Ushioda, E. (2013). Teaching and Researching: Motivation. Routledge. http://dx.doi.org/10.4324/9781315833750

Gamkhet, W. (2008). Research Methodology in Behavioral Science (2nd ed.). Bangkok: Chulalongkorn University Press.

Green, J., Liem, G. A. D., Martin, A. J., Colmar, S., Marsh, H. W., \& McInerney, D. (2012). Academic motivation, self-concept, engagement, and performance in high school: Key processes from a longitudinal perspective. Journal of Adolescence, 35(5), 1111-1122. http://dx.doi.org/10.1016/j.adolescence.2012.02.016

Hannakin, P. (1987). Personnel Management in School (2nd ed.). Bangkok: Nethikul Publishing.

Heisinger, D. A. (1994). Factors that Motivate Washington State Teacher to Participate in Professional Growth and Development. Dissertation abstracts international.

Hopkins, D. (2001). School Empowerment for Real. New York: Routledge Falmer. http://dx.doi.org/10.4324/9780203165799

Jackson, D. R. (1975). A Study of University Administrators Perceptions Related to the Factors of Herzberg's Motivation Hygiene Theory. Dissertation abstracts international.

Kamini, B. (2011). Relationships of Leadership Behavior of School Administrators and Performance Motivation of Municipal Teachers in Chonburi Province (Master thesis, M.Ed. in Educational Administration, Graduate School of Rajanakharind Rajabhat University).

Kasemsin, S. (1988). Mangement (9th ed.). Bangkok: Thaiwattanpanich Publishing.

Ketsakorn, Y. (2011). Leadership and Teamwork. Bangkok: S\&G Graphic Publishing.

Klongklaew, K. (2012). Development of Motivation Strategy of Teachers in the Mid-sized Secondary Schools in Kampangpetch Province (Master thesis, M.Ed. in Educational Administration, Graduate School of Kampangpetch Rajabhat University).

Kocabas, I. (2009). The Effects of Sources of Motivation on Teacher Motivation Levels Education. Chula Vista Catif, 129(4), 724-733.

Kohtbantau, S. (2011). Principles and Theory of Educational Administration (3rd ed.). Bangkok: Panyachon Publishing.

Mailard, K. S., \& Alkins, M. W. (2004). Changing Academic Cultures and Expanding Expectations Motivation Factors Influencing Scholarship at Small Christian Colleges. Christian Higher Education, 3, 373-389. http://dx.doi.org/10.1080/15363750490507384

Milosheff, E. (1990). Factors Contributing to Job Satisfaction at the Community College. Community College Review, 18, 12-22. http://dx.doi.org/10.1177/009155219001800102

Myers, Nancy L. (1993). Job Satisfaction in Adult and Higher Education as Perceived by Art Library Directors. Dissertation abstracts international, 54(4), 1183.

Nesselroade, J. R., \& Cattell, R. B. (Eds.). (2013). Handbook of Multivariate Experimental Psychology. Springer Science \& Business Media. http://dx.doi.org/10.1007/978-1-4613-0893-5

Panpae, P. (2011). Leaders with Changes Management (2nd ed.). Bangkok: Chulalongkokrn University Press.

Randall, C. M. (1987). Job Satisfaction of Chief Administrative Officers of Teacher Education Programs. Dissertation Abstracts International, 48(1), 21-A.

Ray, D. S. (1987). A Study of Motivation Factors of Elementary schools Teacher in a Metropolitan Public School System. Dissertation Abstracts International, 48, 24-A.

Ruthcharoen, T. (2010). Professional in Educational Management and Administration in the Education Reform 
Era (6th ed.). Bangkok: Khoafang Publishing.

Ryan, R. M., \& Deci, E. L. (2000). Self-determination Theory and the Facilitation of Intrinsic Motivation, Social Development, and Well-being. American Psychologist. Senior, B., Organizational Change (2nd ed.). London: Pearson Education. http://dx.doi.org/10.1037/0003-066x.55.1.68

Secretariat of Education. (2010a). Study Report on the Analysis of Educational Development Process of Schools after First Round of Educational Assessment. Bangkok: Chulalongkorn University Press.

Secretariat of Education. (2010b). Study Report on the Research and Development on Teacher Professional Development. Bangkok: Prikwan Graphic Publishing.

Secretariat of Education. (2010c). Study Report on Teacher Competency and Development Guideline on Changing Jurisdiction. Bangkok: Prikwan Graphic Publishing.

Somprasong, N. (1993). Motivation: A Unit in Theory and Practice Guide in Educational Administration (Unit 5-8, pp. 120-165). Nonthaburi: Sukhothai Thammathiracha Open University.

Sonkanok, C. (2010). Factors in Self-development on Scholarly Works Production Achievement of the Private Educational Institutes (Doctoral dissertation, Ed.D., Graduate School of Chulalongkorn University).

Srinil, R. (2009). Developing Guidelines on the Practice of Motivating Staff in Small Schools: Cases of Schools under Jurisdiction of Ayutthaya Educational Service Area 1,2 in Wat Lad Rahong School, Wat Tham Mai School, and Wat Sri Pawang School (Master thesis, M.Ed. in Educational Administration, Graduate School of Prakakhonsri Ayutthaya Rajabhat University).

Srisa-ard, B. (2000). Introduction to Research (6th ed.). Bangkok: Suviriyasan Publishing.

Sunhachavi, A. (2011). Brain-based Learning for Parents and Administrators (3rd ed.). Bangkok: Suviriyasan Publishing.

Tien, F. F. (2008). Kind of Faculty are Motivate to Perform Research by the Desire for Promotion. Higher Education, 55(1), 17-32. http://dx.doi.org/10.1007/s10734-006-9033-5

Uppaphai, N. (2011). Educational Psychology (6th ed.). Bangkok: Chulalongkorn University Press.

Watzke, J. L. (2007). Longitudinal research on beginning teacher development: Complexity as a challenge to concerns-based stage theory. Teaching and Teacher Education, 23(1), 106-122. http://dx.doi.org/10.1016/j.tate.2006.04.001

Wonganutararoch, P. (2010). Psychology for Human Resources. Bangkok: Bangkok Supplementary Media Press. Wongkiatkajorn, P. (2010). Modern Administration Leader. Bangkok: Panyachon Publishing.

Wongwanich, S. (2015). Research on Need Assessment (3rd ed.). Bangkok: Chulalongkorn University Press.

Woolfolk, A. E. (2004). Educational Psychology (9th ed.). Boston: Pearson Education, Inc.

\section{Copyrights}

Copyright for this article is retained by the author(s), with first publication rights granted to the journal.

This is an open-access article distributed under the terms and conditions of the Creative Commons Attribution license (http://creativecommons.org/licenses/by/3.0/). 